\title{
Statistical analysis of the spatiotemporal characteristics of loess landslide in Qingyang area of Gansu province
}

\author{
Zhang binwei ${ }^{1,2,3}$, Liu wanfeng ${ }^{1,3}$, Yang xiao ${ }^{4}$, Wang yue ${ }^{4}$
}

1 Longdong university,School of civil engineering, Qingyang, gansu province, 745000

2Lanzhou jiaotong university,School of civil engineering,Lanzhou, gansu province, 730070

3 Colleges and universities in gansu province "the engineering properties of loess and the engineering application" at the provincial level key laboratory,Qingyang, gansu province, 745000

4 County of gansu province housing and urban and rural construction bureau, The 745700 county, gansu province

Keywords: loess; loess landslide; spatiotemporal analysis; prevention of loess landslide

\begin{abstract}
Qingyang area through frequent field visits, and statistical information analysis, for the "seven county and one area" administrative division in Qingyang area, the distribution curves and statistical characteristic diagram is established, to analyze the characteristics and law of loess landslide distribution in Qingyang area, providing the corresponding theory and reality guidelines for the prevention of loess landslides in Qingyang area, and the conclusion has important reference value for government planning and land resources department.
\end{abstract}

\section{Introduction}

Landslide is a common geological disaster, because it occurs frequently, widely distributed, the economic loss caused by geological disasters ranks in the first except earthquakes. Statistical data show that in Gansu Province, East and West, from 50 at the end of twentieth Century to 1992, a total of 14109 loess landslide are occurred. In recent years, because of the exacerbated economic and social development and population growth, the frequency of the occurrence of geological disasters is increased, causing more and more casualties and property losses [1].

At present, the development of petroleum, coal resources and the deterioration of Qingyang natural environment are in sharp contrast. Because of many factors and complex landslide disaster, to grasp the spatial and temporal distribution characteristics of loess landslide disaster in Qingyang area, make the corresponding statistical data analysis, and put forward the practical meaning of the prevention measures, has important significance for the prevention and control of geological disasters and sustainable economic development in Qingyang area in Gansu province.

\section{Geological hazard regional distribution and the development characteristics of Qingyang area}

Qingyang city is in the south edge of loess plateau area, Erdos basin. the developed geological disasters in this area mainly include collapse, landslide and debris flow and other 12 kinds[2]. in accordance with the Qingyang topography, geological structure, stratum lithology and geological disaster frequency, it can be divided into 2 major areas, namely, the geological disaster prone areas (I), the basic non geological disaster area (II), in which Dongzhiyuan, Zaosheng plateau and the northern hilly region are mild prone areas (I 1), the rest of the region is strongly prone areas (II 2).

(1) It mainly distributs in Zhengning, Ning County, Qingcheng, the part of Xifeng area, the area is 1739.1 square kilometers. The main types of geological disasters are Loess subsidence and ground fissure, which are mild prone areas of geological disaster.

(2) northwest Huan County is arid climate, which is desert and moderate prone areas of disaster, an area is 1713.6 square kilometers;

(3) Other Loess Hilly and gully region are geological disaster prone areas, the occurrence 
frequency is higher, and range is bigger. Types of disasters are mainly landslide, collapse, debris flow, the area is 19468.7 square kilometers, accounted for $71.8 \%$ of the city area.

\section{Analysis of spatial-temporal characteristics of loess landslides in Qingyang area}

\subsection{Analysis of spatial characteristics of loess landslide in Qingyang area}

Landslide is distributed in 7 district and 1 county of Qingyang, the occurrence frequency is high, and Huachi County is the highest frequency of occurrence landslide, Xifeng is the lowest.

We can see that, the loess landslide in Qingyang is mainly distributed in the Southern edge zone of Dongzhi Plateau, along the Rouyuan River, Huanjiang River, Malian river, 202 provincial highway, 303 national highway, 309 and 211 highway.

In Qingyang City, the development and distribution of loess landslide is affected by many factors. The main can be divided into internal and external aspects. The internal factors are the main characteristics of unsaturated loess, large pores, joint development is strong, complex topography and hydrology geology and other aspects; the external factors mainly include engineering activity disturbance, atmospheric precipitation, vegetation resources deteriorated [3].

3.2 Analysis of time characteristics of loess landslides in Qingyang area

Geological disasters occurred in Qingyang in the 6-9 month is most concentrated, the total geological disaster is 83 , accounted for $77 \%$ of the whole year, followed by $2-3$ month of freezing and after thawing period 10-12 month.

the time distribution of geological disasters in Qingyang is basically normal distribution, loess landslide occurred mainly in the autumn season of6-9 month, and more than $80 \%$ of the existed landslide are produced in rainy season.

Figure 1 is the relationship between the occurrence of loess landslide and heavy rain times in Qingyang city during 1981-2010[4], by the polynomial fitting trend line, it can be seen from 1981 to 2003, and the times of loess landslide and rainstorm are positively related.
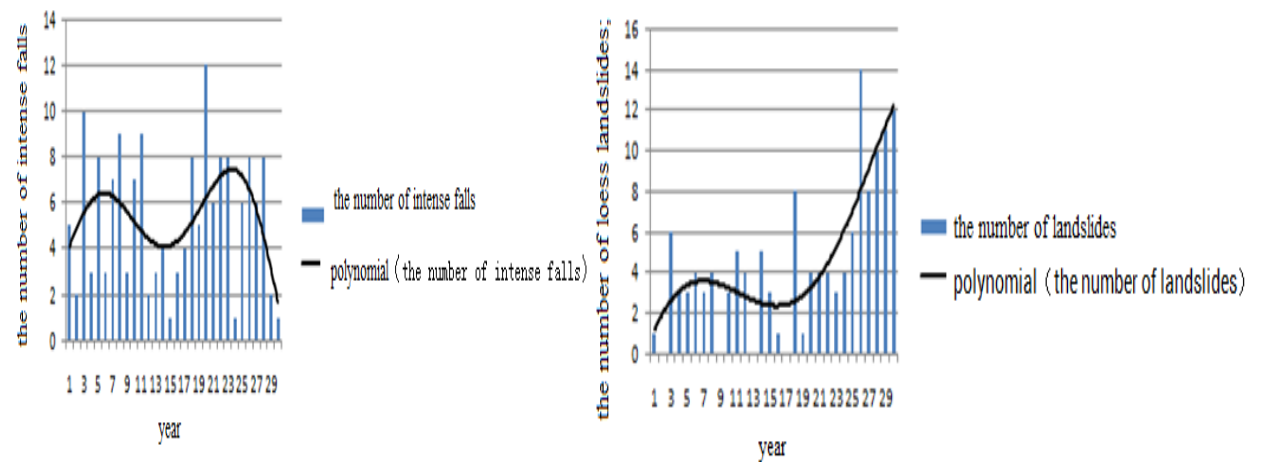

Figure 1 the relational graph of the number of intense falls and loess landslide disaster in recent 30 years in Qingyang area

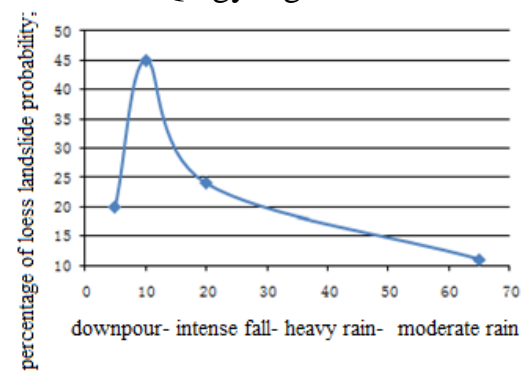

Figure 2 the relation curve of loess landslide and precipitation of oneday 


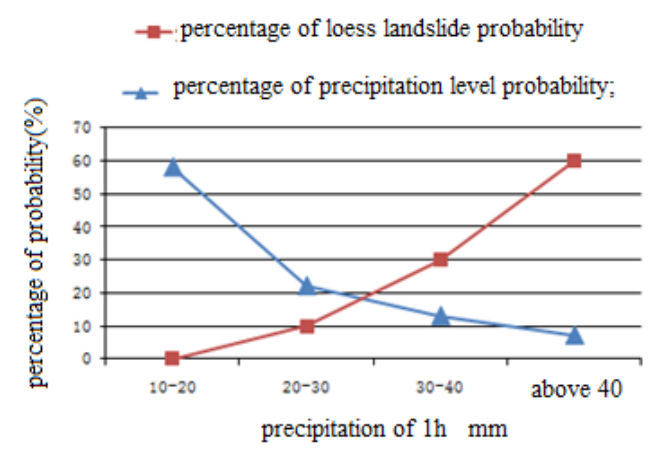

Figure3 the relational graph of loess landslide and precipitation intensity of $1 \mathrm{~h}$

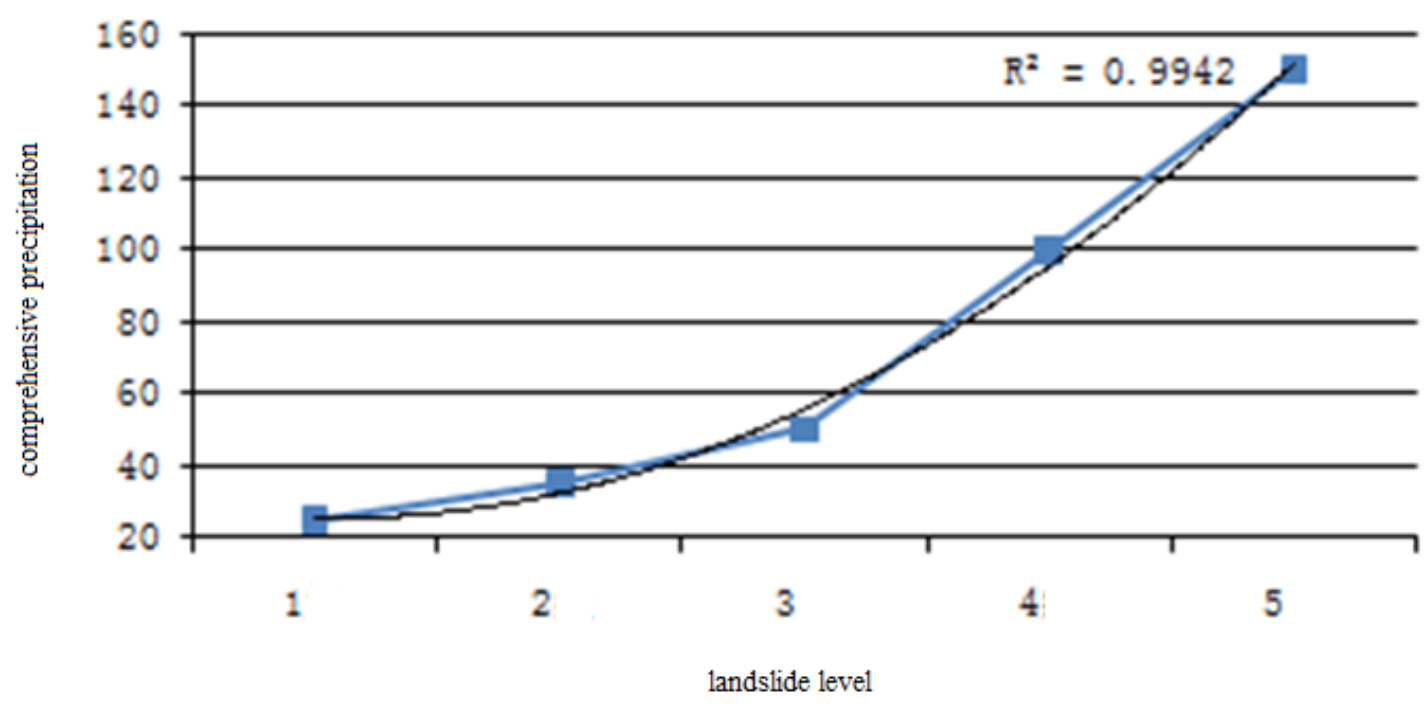

Figure 4 the statistical curve of loess landslide level and comprehensive precipitation; percentage of loess landslide;

3.3 The relationship between the loess landslide disasters and atmospheric precipitation in Qingyang

Figure 2- Figure 4 drawn the relationship between loess landslide and rainfall respectively. As can be seen from Figure 2, when the daily precipitation is intense fall and heavy rain, the probability of landslide occurrence is larger, but in the downpour, landslide percentage is low, which is due to the less heavy rain in Qingyang area. From figure 3, it can be seen that with the increase of $1 \mathrm{~h}$ precipitation intensity, the occurrence probability of loess landslide will be increased it can be seen that with the increase of total precipitation and continuous rainy days to extend, the number of geological disasters appears significantly increased accordingly. Generally, the accumulative rainfall of $5 \mathrm{~d}>50 \mathrm{~mm}$, or the accumulative rainfall of $10 \mathrm{~d}>100 \mathrm{~mm}$, may cause similar disasters.

Considering the loess landslide rainfall condition, the statistical relation of loess landslide level and comprehensive precipitation can be drawn (Figure 4):

Among them, $\mathrm{Rz}$ is the early warning indicators of comprehensive precipitation in loess landslide [5].

The statistical formula, can be as comprehensive evaluation formula for forecasting loess landslide grade in Qingyang, the correlation coefficient is $\mathrm{R}=0.98$. 


\section{Determination of the majority prevention and control space-time of loess landslide in Qingyang}

4.1 determination of the key control period

According to the geological environment, geological disaster distribution characteristics, forming characteristics and inducing factors of Qingyang city, to determine the key period for guarding is the three months of $7,8,9$.

(1) for 1-3 months (snow melt period): in tundra and collapse, landslide and high underground water level area with much more snow covered, it is extremely easy to collapse and landslide. At the same time, it should also pay attention to prevent the collapse, landslide and debris flow disaster in the period of spring irrigation in the edge of Tai (yuan).

(2) for 7-9 months (flood season): flood season is the peak period and the main prevention period of geological disaster, it should focus on the prevention of collapse, landslide, debris flow and other disasters caused by heavy rainfall.

(3) Human engineering activities: various construction activities in the geological disaster prone areas and the strongly disturbance of human engineering activities on the geological environment. Especially for cutting slope, mining and other activities which is easy to induce collapse, landslide, prevention, it should be prevented throughout the year.

4.2 determination of the key control region

(1)Along the highway, railway. in West Changfeng highway, 211 National Road the built Xilei highway, Xiping high speed railway and so on, the geological conditions along them are complex, the distributions of steep and slope are more, evoked in the rainfall and other factors, it is very possible to occur geological disasters such as landslide, collapse. High and steep slope has been built along the road should be an important defense not governance, landslide, collapse may occur under rainfall condition.

(2) Urban construction planning area. In the construction planning area and township distributed in the mountainous area, it should be the focus on preventing engineering cut slopes, foundation excavation and other construction activities which can induce the collapse, landslide and other geological disasters.

(3) Oil and coal Development Zone [6]. It mainly includes the built coal mine such as Ningzheng coal mine, Xinzhuang coal mine, Liuyuanzi coal mine, Mafuchuan coal mine, Tianshuibao coal mine and others. in the region geological condition is complex, geological environment problem is serious, in the induction of rainfall and mining factors, the probability of collapse, landslide, debris flow, ground subsidence and other geological disasters is greater, it should focus on the prevention.

(4) Hills and hilly areas. Hills and hilly areas are the high incidence area of geological disaster, it should focus on strengthening the site selection of rural residential and risk evaluation of geological hazard to strengthen the monitoring, and focus on prevention.

\section{Conclusion}

In this paper, through the statistical analysis of relevant literature and data, the loess geological disaster types and distribution characteristics of Qingyang region are established, the distribution plot of hidden danger of loess landslide in Qingyang area is drawn, the distribution characteristics of Qingyang loess landslide in time and space are analyzed, and theemphasis prevention and control area of loess landslide is established, which has an important practical significance for the prevention and control work of loess landslide geological disaster in Qingyang area.

\section{References}

[1] Zhang Tianfeng, Wang Weitai, Wang Xiwen. The Status and Meteorological Prediction of Geological Calamity in Qingyang City [J]. Arid Meteorology, 2006 (2) :55-59.

[2] Shang Xuefeng, Zhao Yongcheng, Fan Xianyun. The research report of the investigation and 
zoning of geological hazard in Qingyang area of Gansu Province, [R]. Qingyang: Qingyang geological mineral resources authority.2001, 12-27.

[3] Wang Gongxian. Status of research and application of engineering measures for preventing and controlling landslide [J]. Journal of Chinese geological hazard and control, 1996(1):1-9.

[4] Sun Xiujuan, Yang Qiang. Cause of Formation, Characteristic Analysis of Loess Landslides Geological Hazards in East of Gansu and Its Preventive Countermeasures [J]. Site investigation science and technology, 2010(4).

[5] Wang Jiading, Xiao Shufang, Zhang Zhuoyuan. The mechanism for movement of irrigation-induced high-speed loess landslide [J]. Journal of engineering geology, 2001, 9(3): 241-246.

[6] Compilation of geology data and disaster control data in Qingyang city [R]. Qingyang: Qingyang City Land Resources Bureau, 2012. 